\title{
Isoenzymatic Analysis of Four Anopheles (Kerteszia) bellator Dyar \& Knab (Diptera: Culicidae) Populations
}

\author{
Carlos José de Carvalho-Pinto/ ${ }^{+}$, Ricardo Lourenço-de-Oliveira*
}

\author{
Departamento de Microbiologia e Parasitologia, CCB, UFSC, 88040-900 Florianópolis, SC, Brasil *Departamento de \\ Entomologia, Instituto Oswaldo Cruz-Fiocruz, Rio de Janeiro, RJ, Brasil
}

\begin{abstract}
Anopheles bellator is a small silvatic bromelia-breeding mosquito and is a primary human malaria vector species in Southern Brazil. The bromelia-breeding habitat of the species should accompany the Atlantic forest coastal distribution, where bromeliads are abundant. Nonetheless, records on An. bellator collections show a gap in the species geographical distribution. An. bellator has been recorded in Southern Brazil and in the Brazilian states of Bahia and Paraíba. It appers again in the island of Trinidad, in Trinidad and Tobago. The aim of this work was to measure gene flow between different populations of An. bellator collected in the northern and southern extremes of the geographic distribution of this species. Mosquitoes were captured in forest borders in Santa Catarina, São Paulo, and Bahia states in Brazil and in the island of Trinidad in Republic of Trinidad and Tobago. Genetic distances varied between 0.076 and 0.680 , based on enzymatic profiles from 11 distinct isoenzymes. Results indicate the existence of low-level gene flow between Brazilian populations of An. bellator, and a gene flow was even lower between the Brazilian and the Trinidad populations. This finding lead us to hypothesize that An. bellator did not spread along the coast, but reached northeastern areas through inland routes.
\end{abstract}

Key words: isoenzyme - Anopheles bellator - Kerteszia

Malaria vectors in Brazil belong to the subgenera Nyssorhynchus and Kerteszia of the genus Anopheles. Subgenus Kerteszia has 12 described species which are typically small in size and closely associated with forests, distributed from Southern Mexico to Southern Brazil. With the exception of An. bambusicolus Komp, which is found in bamboo internodes, Kerteszia immatures develop in bromeliads (Zavortink 1973, Deane 1986, Consoli \& Lourenço-de-Oliveira 1994). Four species are known malaria vectors: An. neivai Howard, Dyar \& Knab, An. cruzii Dyar \& Knab, An. homunculus Komp, and An. bellator Dyar \& Knab (Zavortink 1973). The geographic distribution of one of these species, An. bellator, a primary human malaria vector species in Southern Brazil (Rachou 1958, Forattini 1962, Coutinho \& Rachou 1966) is intriguing. Zavortink (1973) described its occurrence on the Atlantic coast of South America, from Eastern Venezuela to Southern Brazil. However, no records of An. bellator are reported for the Brazilian Northeastern coastal states of Pará, Piauí, Maranhão, and Ceará. The northernmost report of An. bellator on the Brazilian coast is the state of Paraíba (Aragão 1964). The original description of An. bellator is based on mosquitoes collected on the island of Trinidad, Republic of Trinidad and Tobago. Thus, the geographic distribution of this species is apparently discontinuous.

Interruption of gene exchange between populations can be attributed to several factors including discontinuity of geographic distribution, which may act as a starting

${ }^{+}$Corresponding author. Fax: $+55-48-331.9258$. E-mail: ccb1ccp@ccb.ufsc.br

Received 31 July 2003

Accepted 20 October 2003 point for genetic differentiation, race production, and speciation (Mettler \& Gregg 1969).

The aim of this work was to measure gene flow between different populations of An. bellator collected in the northern and southern extremes of the geographic distribution of this species.

\section{MATERIALS AND METHODS}

Mosquito sampling - All insects included in this study were captured in the Atlantic forest borders of the states of Santa Catarina, São Paulo, and Bahia, Brazil, and in the island of Trinidad in Republic of Trinidad and Tobago (Figure).

Recently captured females were identified using Consoli and Lourenço-de-Oliveira key (1994) and im-mediately stored in liquid nitrogen for isoenzyme analysis.

Isoenzyme electrophoresis was performed in agarose gels as previously described (Hjèrten 1961) with modifications proposed by Salles et al. (1986). Briefly, females were individually crushed in $40 \mu \mathrm{l}$ of lysis buffer $(0.05 \mathrm{mM}$ Tris- $\mathrm{HCl} \mathrm{pH}=8.0,0.01 \mathrm{mM}$ EDTA, $0.01 \mathrm{mM} \varepsilon$-amino $\mathrm{n}$ caproic acid, and $1 \%$ Triton-100X) in 96 well plates in ice bath.

A total of sixteen enzyme systems was analyzed by agarose gel electrophoresis using $2 \mu \mathrm{l}$ of the lysate for approximately $2 \mathrm{~h}$ at $4^{\circ} \mathrm{C}$ in appropriate buffers. Detection of each enzyme was carried out overlaying the electrophoresis gel with a solution of $10 \%$ agarose supplemented with specific substrates, co-enzymes and co-factors (for more details see Rosa-Freitas et al. 1992). After development for 20-60 min at room temperature, in darkness, the enzymatic reactions were stopped by addition of $5 \%$ acetic acid. Gels were then dried at room temperature and analysis of genotypic frequencies was performed using BYOSIS software (Swofford \& Selander 1981). 


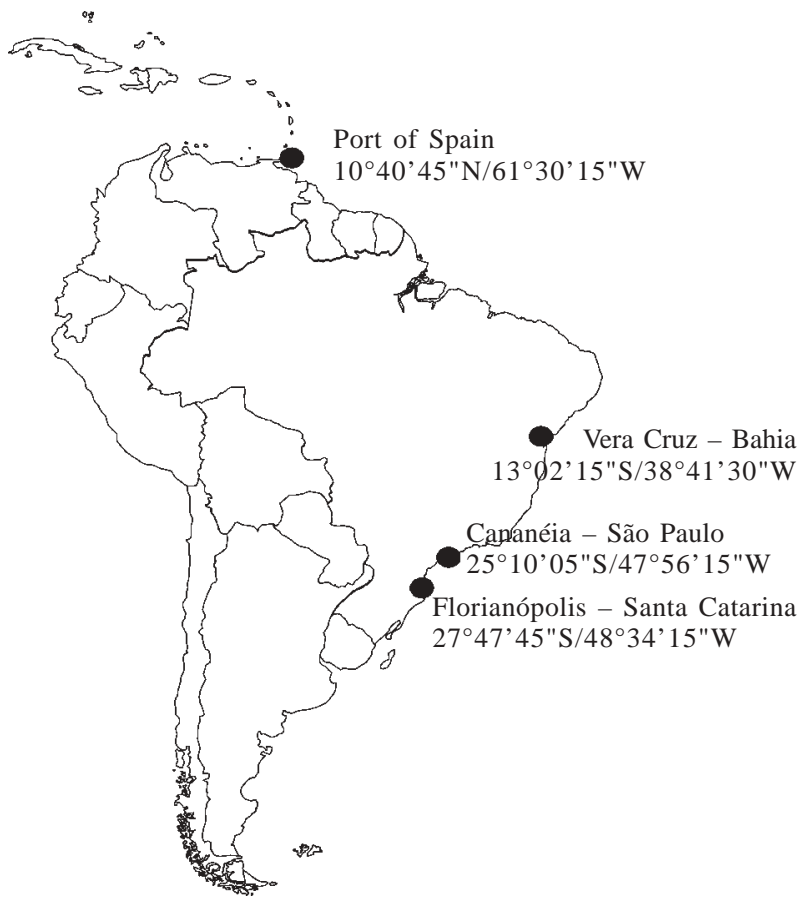

Source of specimens of Anopheles bellator used in isoezyme analyses.

\section{RESULTS}

From a total of 16 enzymatic systems tested, 11 revealed clear banding patterns [phosfoglucomutase - EC 5.4.2.2 (PGM), hexokinase - E.C. 2.7.1.1 (HK), mannose-6phosphate isomerase EC 5.3.1.8 (MPI), malic enzyme EC 1.1.1.40 (ME), malate dehydrogenase - E.C. 1.1.1.37 (MDH), esterase - EC 3.1.1.1 (EST), glucose-6-phosphate isomerase- EC 5.3.1.9 (GPI), isocitrate dehydrogenase EC 1.1.1.42 (IDH), leucyl aminopeptidase - EC 3.4.11.1 (PEP-1), tripeptide aminopeptidase - EC 3.4.11.4 (PEP-2), membrane alanyl aminopeptidase - EC 3.4.11.2 (PEP-3)], with ME showing two distinct loci, thus allowing the distinction of a total of 12 loci. Allelic frequencies of all An. bellator loci analyzed are presented in Table I. A monomorphic pattern was observed for HK, ME-2, and GPI enzymes in all samples. MPI was monomorphic for Bahia and Trinidad populations, and IDH for Santa Catarina, São Paulo, and Trinidad (Table I).

The mean number of alleles per locus ranged from 2.1 to 2.6 and the percentage of polymorphic loci ranged from 58.3 in Trinidad to $66.7 \%$ for Santa Catarina, São Paulo, and Bahia populations. The mean heterozygosity among the studied samples ranged from 0.210 to 0.319 (Table II).

The genetic distance calculated according to Nei (1978) varied between 0.076 and and 0.680 . Genetic identities varied from 0.386 to 0.927 (Table III).

The values of Fis and Fit were 0.090 and 0.330, respectively. The $\mathrm{F}_{\mathrm{ST}}$ value was 0.263 (Table IV) and the inferred migrants per generation were 0.70 between all An. bellator populations studied. By excluding the Trinidad population from the analysis, the Fst value was reduced to 0.151 and the number of migrants per generation increased to 1.4 .
TABLE I

Allelic frequencies of Anopheles bellator populations Santa Catarina (SC), São Paulo (SP), Bahia (BA), Trinidad (TR), n = individuals

\begin{tabular}{|c|c|c|c|c|}
\hline \multirow[b]{2}{*}{ Locus } & \multicolumn{4}{|c|}{ Populations } \\
\hline & $\mathrm{SC}$ & SP & BA & TR \\
\hline \multicolumn{5}{|l|}{$\overline{\mathrm{PGM}}$} \\
\hline $\mathrm{n}$ & 30 & 30 & 30 & 31 \\
\hline A & 0.000 & 0.000 & 0.033 & 0.016 \\
\hline B & 0.900 & 0.617 & 0.717 & 0.774 \\
\hline $\mathrm{C}$ & 0.100 & 0.367 & 0.217 & 0.161 \\
\hline D & 0.000 & 0.000 & 0.033 & 0.048 \\
\hline $\mathrm{E}$ & 0.000 & 0.017 & 0.000 & 0.000 \\
\hline \multicolumn{5}{|l|}{ HK } \\
\hline $\mathrm{n}$ & 30 & 30 & 30 & 30 \\
\hline A & 1.000 & 1.000 & 1.000 & 1.000 \\
\hline \multicolumn{5}{|l|}{ MPI } \\
\hline $\mathrm{n}$ & 36 & 30 & 30 & 30 \\
\hline $\mathrm{A}$ & 0.000 & 0.000 & 0.000 & 1.000 \\
\hline $\mathrm{B}$ & 0.375 & 0.483 & 1.000 & 0.000 \\
\hline $\mathrm{C}$ & 0.625 & 0.517 & 0.000 & 0.000 \\
\hline \multicolumn{5}{|l|}{ ME-1 } \\
\hline $\mathrm{n}$ & 30 & 31 & 30 & 30 \\
\hline $\mathrm{A}$ & 0.000 & 0.161 & 0.167 & 0.983 \\
\hline $\mathrm{B}$ & 0.200 & 0.258 & 0.600 & 0.017 \\
\hline $\mathrm{C}$ & 0.800 & 0.484 & 0.233 & 0.000 \\
\hline $\mathrm{D}$ & 0.000 & 0.097 & 0.000 & 0.000 \\
\hline \multicolumn{5}{|l|}{ ME-2 } \\
\hline $\mathrm{n}$ & 30 & 30 & 30 & 30 \\
\hline A & 1.000 & 1.000 & 1.000 & 1.000 \\
\hline \multicolumn{5}{|l|}{$\mathrm{MDH}$} \\
\hline $\mathrm{n}$ & 24 & 30 & 29 & 30 \\
\hline A & 0.104 & 0.000 & 0.034 & 0.367 \\
\hline $\mathrm{B}$ & 0.250 & 0.333 & 0.345 & 0.317 \\
\hline $\mathrm{C}$ & 0.042 & 0.000 & 0.466 & 0.000 \\
\hline $\mathrm{D}$ & 0.604 & 0.667 & 0.103 & 0.317 \\
\hline $\mathrm{E}$ & 0.000 & 0.000 & 0.052 & 0.000 \\
\hline \multicolumn{5}{|l|}{ EST } \\
\hline $\mathrm{n}$ & 30 & 29 & 30 & 30 \\
\hline A & 0.067 & 0.259 & 0.000 & 0.050 \\
\hline B & 0.617 & 0.138 & 0.167 & 0.000 \\
\hline $\mathrm{C}$ & 0.317 & 0.500 & 0.350 & 0.950 \\
\hline $\mathrm{D}$ & 0.000 & 0.103 & 0.483 & 0.000 \\
\hline \multicolumn{5}{|l|}{ GPI } \\
\hline $\mathrm{n}$ & 30 & 30 & 30 & 30 \\
\hline A & 1.000 & 1.000 & 1.000 & 1.000 \\
\hline \multicolumn{5}{|l|}{ IDH } \\
\hline $\mathrm{n}$ & 30 & 30 & 30 & 30 \\
\hline A & 0.000 & 0.000 & 0.067 & 0.000 \\
\hline B & 1.000 & 1.000 & 0.750 & 1.000 \\
\hline C & 0.000 & 0.000 & 0.183 & 0.000 \\
\hline \multicolumn{5}{|l|}{ PEP-1 } \\
\hline $\mathrm{n}$ & 30 & 30 & 30 & 30 \\
\hline A & 0.333 & 0.050 & 0.000 & 0.100 \\
\hline B & 0.000 & 0.617 & 0.333 & 0.000 \\
\hline $\mathrm{C}$ & 0.567 & 0.300 & 0.667 & 0.450 \\
\hline D & 0.100 & 0.033 & 0.000 & 0.450 \\
\hline \multicolumn{5}{|l|}{ PEP-2 } \\
\hline $\mathrm{n}$ & 32 & 30 & 30 & 32 \\
\hline A & 0.000 & 0.017 & 0.050 & 0.109 \\
\hline B & 0.531 & 0.750 & 0.683 & 0.516 \\
\hline $\mathrm{C}$ & 0.469 & 0.233 & 0.017 & 0.313 \\
\hline $\mathrm{D}$ & 0.000 & 0.033 & 0.250 & 0.063 \\
\hline \multicolumn{5}{|l|}{ PEP-3 } \\
\hline $\mathrm{n}$ & 29 & 32 & 24 & 30 \\
\hline A & 0.328 & 0.281 & 0.208 & 0.267 \\
\hline B & 0.586 & 0.500 & 0.771 & 0.067 \\
\hline C & 0.086 & 0.219 & 0.021 & 0.667 \\
\hline
\end{tabular}


TABLE II

Mean of sample per locus, mean of alleles per locus, percentage of polymorphic loci, and mean heterozygozity for four Anopheles bellator populations Santa Catarina (SC), São Paulo (SP), Bahia (BA), Trinidad (TR)

\begin{tabular}{|c|c|c|c|c|c|}
\hline \multirow[b]{2}{*}{ Population } & \multirow{2}{*}{$\begin{array}{c}\text { Mean sample } \\
\text { size/locus }\end{array}$} & \multirow{2}{*}{$\begin{array}{c}\text { Mean number of } \\
\text { alleles/locus }\end{array}$} & \multirow{2}{*}{$\begin{array}{c}\text { Percentage of } \\
\text { polymorphic locus }\end{array}$} & \multicolumn{2}{|c|}{ Mean heterozygosity } \\
\hline & & & & Ho & $\mathrm{He}$ \\
\hline $\mathrm{SC}$ & $30.1 \pm 0.8$ & $2.1 \pm 0.3$ & 66.7 & $0.274 \pm 0.066$ & $0.309 \pm 0.073$ \\
\hline SP & $30.2 \pm 0.2$ & $2.4 \pm 0.4$ & 66.7 & $0.319 \pm 0.078$ & $0.362 \pm 0.081$ \\
\hline $\mathrm{BA}$ & $29.4 \pm 0.5$ & $2.6 \pm 0.4$ & 66.7 & $0.312 \pm 0.074$ & $0.334 \pm 0.75$ \\
\hline TR & $30.3 \pm 0.2$ & $2.2 \pm 0.3$ & 58.3 & $0.210 \pm 0.072$ & $0.241 \pm 0.083$ \\
\hline
\end{tabular}

TABLE III

Matrix of genetic identities (above diagonal) and distances (below diagonal) (Nei 1978) among four Anopheles bellator populations

\begin{tabular}{lcccc}
\hline Population & SC & SP & BA & TR \\
\hline SC & - & 0,927 & 0.829 & 0.721 \\
SP & 0.076 & - & 0.876 & 0.764 \\
BA & 0.187 & 0.132 & - & 0.680 \\
TR & 0.327 & 0.269 & 0.386 & - \\
\hline
\end{tabular}

SC: Santa CAtarina; SP: São Paulo; BA: Bahia; TR: Trinidad

TABLE IV

Wright fixation indicies (Fis, Fit, and Fst) for four Anopheles bellator populations

\begin{tabular}{lrrc}
\hline Locus & \multicolumn{1}{c}{$\mathrm{F}_{\mathrm{IS}}$} & \multicolumn{1}{c}{$\mathrm{F}_{\mathrm{IT}}$} & $\mathrm{F}_{\mathrm{ST}}$ \\
\hline Phosfoglucomutase & -0.100 & -0.041 & 0.054 \\
Mannose-6-phosphate isomerase & 0.248 & 0.716 & 0.622 \\
Malic enzyme-1 & -0.002 & 0.417 & 0.418 \\
Malate dehydrogenase & 0.150 & 0.288 & 0.162 \\
Esterase & 0.066 & 0.311 & 0.262 \\
Isocitrate dehydrogenase & 0.082 & 0.228 & 0.159 \\
Leucyl aminopeptidase-1 & 0.180 & 0.345 & 0.202 \\
Leucyl aminopeptidase-2 & 0.057 & 0.142 & 0.090 \\
Leucyl aminopeptidase-3 & 0.119 & 0.303 & 0.208 \\
\hline Mean & 0.090 & 0.330 & 0.263 \\
\hline
\end{tabular}

\section{DISCUSSION}

Interest in better morphological characterization and in intrapopulational comparisons of Neotropical anopheline species has increased during the last few years, mostly focusing on characterization of cryptic species complexes (Conn 1993, Linley et al. 1996, Lounibos et al. 1998, Rosa-Freitas et al. 1998, Manguin et al. 1999, Calle et al. 2002, Sallum et al. 2002, Santos et al. 2003). Most of these studies concern subgenus Nyssorhynchus species due to their major role in malaria transmission in South and Central America. Insufficient data are available concerning species of the subgenus Kerteszia, probably due to the difficulty of maintaining these species under laboratory conditions and for many areas, the low number of captured mosquitoes.

According to Thorpe and Solé-Cava (1994), genetic distances greater than 0.35 are observed for individuals belonging to cryptic species complexes. Despite the genetic distance observed between Bahia and Trinidad populations, genetic distances under 0.35 were observed between samples from Trinidad and the southernmost extreme of An. bellator distribution (São Paulo and Santa Catarina).

Fst values observed for 4 populations of An. bellator were relatively high. Fst values higher than 0.05 indicate the existence of a moderate genetic structured population (Wright 1978). A low number of migrants per generation (0.7) reveal the existence of different genetic structured An. bellator populations. When only the Brazilian populations are analyzed there is a slightly increase in the number of migrants per generation (1.4). These results indicate the existence of low-level gene flow between Brazilian populations of An. bellator, and an even lower gene flow between those and the Trinidad population. Despite these findings, we cannot explain the apparent interruption in the geographical distribution of $A n$. bellator in Northern South America, where with exception of Bahia, Paraíba, and Trinidad the species has never been collected. According to Aragão (1964), An. bellator originated in the Atlantic coastal formations of the Guyanas, from were it has spread throughout the continent. Considering that there is no report of $A n$. bellator along hundreds of kilometers in the Northern Brazilian coast, we may infer that this species possibly did not spread along the coast, but reached Northeastern Brazil through inland routes. Thus, the greater genetic distance observed among Bahia and Trinidad populations can be explained if we consider these areas the extremes of An. bellator geographic distribution. Moreover, we must consider the possibility of a recent geographical split of these populations, not allowing enough time for speciation.

\section{ACKNOWLEDGEMENTS}

To Dr Dave Chadee for providing us mosquito samples from Trinidad and Dr Richard Wilkerson for revising the manuscript and for suggestions.

\section{REFERENCES}

Aragão MB 1964. Distribuição geográfica e abundância das espécies de Anopheles (Kerteszia) (Diptera, Culicidae). Rev Bras Malariol Doen Trop 16: 73-109.

Calle DAL, Quiñones ML, Erazo HF, Jaramillo, NO 2002. Morphometric discrimination of females of five species of Anopheles of the subgenus Nyssorhynchus from Southern and Northwest Colombia. Mem Inst Oswaldo Cruz 97: 1191-1195.

Conn J 1993. A genetic study of the malaria vector Anopheles nuneztovari from western Venezuela. J Am Mosq Control Assoc 6: 400-405. 
Consoli RAGB, Lourenço-de-Oliveira R 1994. Principais Mosquitos de Importância Sanitária no Brasil, Fiocruz, Rio de Janeiro, $225 \mathrm{pp}$.

Coutinho JO, Rachou R 1966. Dados sobre a biologia e a capacidade vetora de malária dos anofelinos do sub-gênero Kerteszia em condições naturais. Rev Bras Malariol Doen Trop 18: 557-579.

Deane LM 1986. Malaria vectors in Brazil. Mem Inst Oswaldo Cruz 81 (Suppl. II): 5-14.

Forattini OP 1962. Entomologia Médica, Vol. I, Faculdade de Higiene e Saúde Pública, São Paulo, 662 pp.

Hjèrten S 1961. Agarose as a anticonventional agent in zone electrophoresis. Biochem Biophys Acta 52: 514-517.

Linley JR, Lounibos LP, Conn J, Duzak D, Nishimura N 1996. A description and morphometric comparison of eggs from eight geographic populations of the South American malaria vector Anopheles (Nyssorhynchus) nuneztovari (Diptera: Culicidae). J Am Mosq Control Assoc 12: 275-292.

Lounibos LP, Wilkerson RC, Conn JE, Hribar LJ, Fritz GN, Danoff-Burg JA 1998. Morphological, molecular, and chromosomal discrimination of cryptic Anopheles (Nyssorhynchus) (Diptera: Culicidae) from South America. $J$ Med Entomol 35: 830-838.

Manguin S, Wilkerson RC, Conn JE, Rubio-Palis Y, DanoffBurg JA, Roberts DR 1999. Population structure of the primary malaria vector in South America, Anopheles darlingi, using isozyme, random amplified polymorphic DNA, internal transcribed spacer 2, and morphologic markers. Am J Trop Med Hyg 60: 364-376

Mettler LE, Greeg TG 1969. Population Genetics and Evolution, Pratice-Hall, London, 212 pp.

Nei M 1978. Estimation of average heterozygosity and genetic distance from a small number of indiviuals. Genetics 89: 583-590.

Rachou RG 1958. Anofelinos do Brasil: comportamento das espécies vetoras de malária. Rev Bras Malariol Doen Trop 10: 145-181.

Rosa-Freitas MG, Broomfield G, Priestman A, Milligan PJ,
Momen H, Molyneux DH 1992. Cuticular hydrocarbons, isoenzymes, and behavior of three populations of Anopheles darlingi from Brazil. J Am Mosq Control Assoc 8: 357-366.

Rosa-Freitas MG, Lourenço-de-Oliveira R, Carvalho-Pinto CJ, Flores-Mendoza C, Silva-do-Nascimento TF 1998. Anopheline species complexes in Brazil. Current knowledge of those related to malaria transmission. Mem Inst Oswaldo Cruz 95: 651-655.

Salles CA, Silva AR, Momen H 1986. Enzyme typing and phenetic relationships in Vibrio cholerae. Rev Bras Genet 9: 407-419.

Sallum MAM, Bergo ES, Flores DC, Forattini OP 2002. Systematic studies on Anopheles galvaoi Causey, Deane \& Deane from the subgenus Nysssorhynchus Blanchard (Diptera: Culicidae). Mem Inst Oswaldo Cruz 97: 11771189.

Santos JMM, Maia JF, Tadei WP, Rodrigues GAD 2003. Isoenzymatic variability among five Anopheles species belonging to the Nyssorhynchus and Anopheles subgenera of the Amazon region, Brazil. Mem Inst Oswaldo Cruz 98: 247-254.

Swofford DL, Selander RB 1981. BIOSYS-1: a FORTRAN program for the comprehensive analysis of electrophoretic data in population genetics and systematics. $J$ Hered 72 : 281-283.

Thorpe JP, Solé-Cava AM 1994. The use of allozyme electrophoreis in invertebrate systematics. Zool Scr 23: 3-18.

Wilkerson R, Peyton EL 1991. The Brazilian malaria vector Anopheles (Kerteszia) cruzii: life stages and biology (Diptera: Culicidae). Mosq Syst 23: 110-122.

Wright S 1978. Evolution and Genetics of Populations. Variability within and among Natural Populations, 4, University of Chicago, US, $580 \mathrm{pp}$.

Zavortink TJ 1973. Mosquito studies (Diptera: Culicadae). XXIX. A review of the subgenus Kerteszia of Anopheles. Cont Am Entomol Inst 9: 1-54. 